\title{
Antegrade stent placement in laparoscopic upper urinary tract surgery. Is there an easy way?
}

\author{
Kaan Gökçen ${ }^{1}$, Gökhan Gökçe ${ }^{1}$, Yakup Kordan², Emre Kıraç${ }^{1}$, Gökçe Dündar ${ }^{3}$, Emin Yener Gültekin ${ }^{1}$ \\ ${ }^{1}$ Department of Urology, Cumhuriyet University, Sivas, Turkey \\ ${ }^{2}$ Department of Urology, Koç University, Istanbul, Turkey \\ ${ }^{3}$ Department of Urology, Cizre State Hospital, Cizre, Turkey
}

Videosurgery Miniinv 2019; 14 (1): 102-106

DOI: https://doi.org/10.5114/wiitm.2018.77260

\begin{abstract}
Introduction: Antegrade placement of double J stents in laparoscopy is considered a challenging and time-consuming process due to limitations regarding stent flexibility.

Aim: To describe the method we used to facilitate the antegrade placement of intracorporeal stents in laparoscopic upper urinary tract (LUUT) surgery and report its results.

Material and methods: Data obtained from 42 consecutive patients who had stents placed antegradely in laparoscopic pyeloplasty or in laparoscopic ureterolithotomy for middle-upper ureteral stones were retrospectively evaluated. The mean age of the patients was $30.1 \pm 18.6$ (10 months-68 years) and 13 patients were in the paediatric age group. All patients in the paediatric age group underwent laparoscopic pyeloplasty.

Results: The mean operative time for the 42 total cases, of which 32 underwent laparoscopic dismembered pyeloplasty and 10 laparoscopic ureterolithotomy, was $126.9 \pm 33.5$ (70-200) min and the intraoperative stent placement time was calculated as $2.61 \pm 0.8$ (1.5-5) min. The patients, who had a mean hospitalization time of $2.8 \pm 0.9$ (2-5) months, required no additional interventions and no complications were encountered intraoperatively. In the patient series that had a mean follow-up time of $17.4 \pm 11.3$ (1-35), it was determined only in 1 patient that the distal tip of the stent had not been in the bladder.

Conclusions: The described modified antegrade stent placement technique is a practical method that is safe for all LUUT cases in both paediatric and adult age groups and it has been shown to produce successful outcomes and to be time-saving.
\end{abstract}

Key words: laparoscopy, stenting, pyeloplasty, pelviureteral anastomoses, upper ureteral stones.

\section{Introduction}

Laparoscopic upper urinary tract procedures are frequently used today in the treatment of uropathologies that cause obstruction of the upper urinary tract such as ureteropelvic junction obstruction (UPJO) and middle-upper ureteral stones. Although extracorporeal shock wave lithotripsy (SWL) and ureteroscopic lithotripsy are the recommended first- line treatments especially for patients with proximal ureteral stones, in the case of patients with large ureteral stones where the treatment has failed, laparoscopic ureterolithotomy is applied as an alternative to open surgery procedures [1-3].

Being one of the most important causes of antenatal hydronephrosis, UPJO is encountered twice as frequently in male newborns as in females and has a total incidence rate of $1 / 1500$ [4]. Although

\section{Address for correspondence}

Kaan Gökçen Assist. Prof., Department of Urology, Cumhuriyet University, Cumhuriyet University Hospital, 58010 Sivas, Turkey,

phone: +90 346 258000, e-mail: kaangokcen@hotmail.com 
laparoscopic dismembered pyeloplasty and open pyeloplasty demonstrate similar rates of success in the treatment of UPJO, the laparoscopic technique is a safe, minimally invasive treatment modality that results in lower complication rates, shorter hospitalization time, and less postoperative pain, as well as better cosmetic outcomes [5-7].

Passage of urine following upper urinary tract surgery is achieved by external drainage methods in which a nephrostomy tube is inserted or internal drainage methods where ureteral stents such as the $D / J$ stent are placed. D/J stent use, which is frequently preferred in laparoscopic upper urinary tract (LUUT) surgery, provides advantages such as the prevention of transient ureteral obstruction caused by ureteral oedema and haematoma and the avoidance of anastomotic urinary leaks [8]. Most of the time, the antegrade placement of double J stents in the laparoscopic technique is considered a challenging and time-consuming process by surgeons due to limitations regarding the flexibility of the stent, the curving of the distal tip of the stent, and the restricted bending angle of the laparoscopic equipment. A limited number of modifications have been developed in order to overcome these limitations and make the antegrade stent placement procedure easier and more practical.

\section{Aim}

In this study, the results of the antegrade D/J stent placement method by means of Amplatz renal dilators that we used during LUUT surgery performed on both adult and paediatric case groups are reported.

\section{Material and methods}

A total of 42 patients with 13 in the paediatric age group who had been treated between May 2015 and December 2017 by the transperitoneal method of LUUT surgery in which D/J stents had been antegradely placed in all cases were retrospectively evaluated. All of the child patients underwent laparoscopic dismembered pyeloplasty. Of the 32 patients who underwent laparoscopic Anderson-Hynes dismembered pyeloplasty, 13 were paediatric and 19 were adult patients, and the remaining 10 adult patients had their middle and upper ureteral stones treated with laparoscopic ureterolithotomy. The LUUT procedures that were performed at the Cumhuriyet Uni- versity Health Services and Research Hospital were performed by a single surgeon (K.G.) after obtaining written consent from the patients.

\section{Operative technique}

All LUUT procedures were performed under general anaesthesia by the transperitoneal method in the lateral decubitus position at $60^{\circ}$ following the administration of single dose antibiotic prophylaxis. In child patients, following the placement of a $5 \mathrm{~mm}$ camera trocar by the open technique through the umbilicus, two $5 \mathrm{~mm}$ working trocars were inserted. In adults, a pneumoperitoneum was created by $\mathrm{CO}_{2}$ insufflation using a Veress needle and a total of three ports were used, which comprised a $10 \mathrm{~mm}$ camera port, and one $10 \mathrm{~mm}$ and one $5 \mathrm{~mm}$ working trocar. An additional $5 \mathrm{~mm}$ trocar was placed for the purpose of retraction when necessary.

\section{Antegrade stent insertion technique}

The antegrade $\mathrm{D} / \mathrm{J}$ stent placement procedure was performed following the completion of the anastomosis of the posterior suture line in the laparoscopic dismembered pyeloplasty operation, and following the extraction of the stone through the ureterotomy incision in the laparoscopic ureterolithotomy procedure. The closed end of the $4 \mathrm{Fr}$ $\mathrm{D} / \mathrm{J}$ stent used in paediatric patients and 4.8 $\mathrm{Fr} \mathrm{D} / \mathrm{J}$ stent used in adult patients was advanced into the bladder through the proximal ureter with the help of $10 \mathrm{Fr}$ or $14 \mathrm{Fr}$ Amplatz dilators passed through the trocar. In case of difficulties in the placement of the distal tip, it was attempted to advance the distal tip into the bladder by retracting the guidewire within the D/J stent for about $1 \mathrm{~cm}$ and loosening the distal tip. The guidewire inside the $\mathrm{D} / \mathrm{J}$ stent and the Amplatz dilator used to help guide the stent were removed through the trocar, and the proximal tip of the stent was advanced up to the pelvis with the help of a grasper under laparoscopic vision (Photo 1). After the conclusion of the ureteral stent placement procedure, the anastomosis of the anterior line in pyeloplasty and the closure of the ureterotomy incision in ureterolithotomy were completed. The duration of antegrade $\mathrm{D} / \mathrm{J}$ stent placement, the time between the introduction of the D/J stent through the trocar within the Amplatz renal dilator and the completion of stent placement, was retrospectively calculated based on visual records. In the intraoper- 

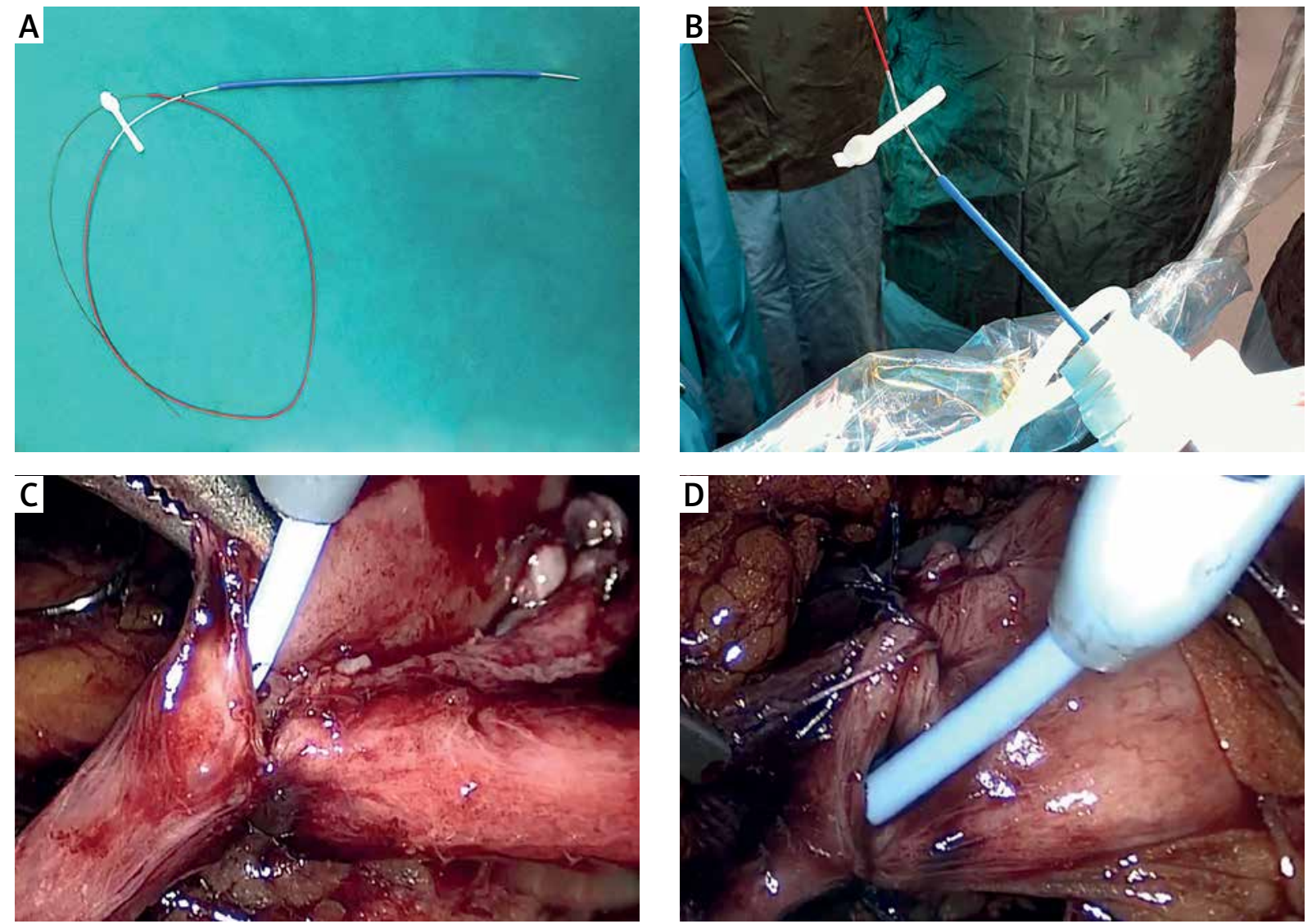

Photo 1. Preoperative preparation of the D/J stent to be inserted through a suitable Amplatz dilator and its intracorporeal antegrade placement

ative period, the precision of the D/J stent placement was not verified with any radiological methods.

All patients underwent kidney ureter bladder (KUB) radiography on the 1 st postoperative day and the placements of the stents were verified. In all cases, the Foley catheter was removed on the $2^{\text {nd }}$ postoperative day, and the drains were removed when they receded below $30 \mathrm{ml}$ and the patient was discharged. The D/J stents were removed at the $4-6^{\text {th }}$ postoperative week; all patients were requested to have urinary tract ultrasonography done in the $3^{\text {rd }}$ postoperative month and the patients who underwent pyeloplasty were asked to present for a follow-up examination in the $6^{\text {th }}$ postoperative month with MAG-3 renal scintigraphy results.

\section{Results}

Of the total 42 patients who underwent LUUT surgery, 31 were male and 11 were female. Thirteen patients were in the paediatric group and were treat- ed with laparoscopic pyeloplasty, and of the remaining 29 adult patients, 19 underwent laparoscopic pyeloplasty and 10 laparoscopic ureterolithotomy. The mean age of the child patients was $6.8 \pm 5.1$ years (10 months to 16 years) with 2 in the infant group. The mean age of the adult patients was $40.5 \pm 14.3$ (19-68). The mean operative time for all cases was $126.9 \pm 33.5$ (70-200) min; and intraoperative complications or a need for conversion to open surgery were not encountered in any patients. The average amount of blood loss during surgery was $28.2 \pm 21.6$ $(10-105) \mathrm{ml}$ and none of the cases required intraoperative erythrocyte transfusion. The duration of laparoscopic antegrade stent placement was calculated as $2.61 \pm 0.8(1.5-5) \mathrm{min}$. The antegrade D/J stent placement procedure was performed according to the described laparoscopic method in all cases and no additional manoeuvres or interventions were needed. The mean follow-up period was calculated as $17.4 \pm 11.3(1-35)$ months. The transperitoneal approach was preferred in all cases except in 2 cas- 
es of middle ureteral stones that were performed by a retroperitoneal approach. The preoperative, intraoperative, and postoperative demographic data of all cases are presented in Table I.

It was determined on the first postoperative day, when the $D / J$ stents of the patients were checked with KUB, that the distal end of the stent had not entered the bladder only in one of the paediatric cases. The D/J stent was replaced with ureteroscopy retrogradely on the third postoperative day in consequence of abdominal pain being reported by the child and $300 \mathrm{ml}$ of urine leakage through the drain per day. The mean hospitalization time was calculated as $2.8 \pm 0.9$ (2-5) days for all patients. Deterioration of hydronephrosis or kidney function was not encountered in any patients in the follow-up period.

\section{Discussion}

In parallel to the development of minimally invasive methods, the laparoscopic dismembered pyeloplasty technique has been a preferred method in recent years as it produces success rates comparable to open surgery in all patient groups [7]. Similarly, laparoscopic ureterolithotomy is considered an effective method with successful results especially in the treatment of cases of large impacted proximal and middle ureteral stones, where it is used either primarily or after unsuccessful SWL and ureterorenoscopy procedures [9, 10]. Although there have been reported studies focusing on the route and implementation of ureteral stent placement with the increasing popularity of the antegrade and retrograde techniques, a consensus on which method is more convenient and ideal has not been reached yet.

While it has been reported in studies conducted on the route of ureteral stent placement that the retrograde placement of the $D / J$ stent prolonged the duration of the surgery due to the need to reposition the patient, there have also been contrasting reports suggesting that the retrograde placement was more successful and had lower complication rates [11-13]. Another subject of discussion regarding the retrograde placement of the $D / J$ stent is whether it should be done before or after the pyeloplasty procedure. While the presence of a stent placed prior to laparoscopic pyeloplasty hinders dissection as it drains the renal pelvis and obstructs the ureteral spatulation and suturing, stents placed postopera- tively may come out from between the sutures on the anastomosis line [14].

Various modifications have been developed over time in order to overcome the difficulties associated with antegrade stent placement and its time-consuming properties; however, most of those have described a necessity for an additional intervention using a chiba needle, angiocatheter, or innovative instruments [15-19]. No additional interventions were needed in the placement of stents that we applied in our study by means of Amplatz dilators and the dilators were inserted through the existing cranial trocar. Other advantages of this technique are that it allows easier manipulation of the tip of the stent, offers simpler implementation, does not require fluoroscopic control, and that preoperative cystoscopy is not performed. A similar technique has only been described in cases of laparoscopic pyeloplasty performed on child cases, and resembling our study, the described technique was shown to be feasible with quick implementation [20]. However, unlike the described study, it was implemented in both adult and

Table I. Preoperative, intraoperative, and postoperative data of patients

\begin{tabular}{|c|c|}
\hline Parameter & Value \\
\hline Total no. of patients & 42 \\
\hline No. of paediatric/adult patients & $13 / 29$ \\
\hline $\begin{array}{l}\text { Age, mean } \pm \text { SD (range); } \\
\text { all patients [years] }\end{array}$ & $\begin{array}{c}30.1 \pm 18.6 \\
\text { (10 months }-68 \text { years })\end{array}$ \\
\hline No. of female/male patients & $11 / 31$ \\
\hline $\begin{array}{l}\text { No. of ureterolithotomy/ } \\
\text { pyeloplasty procedures }\end{array}$ & $10 / 32$ \\
\hline No. of left/right procedures & $24 / 18$ \\
\hline $\begin{array}{l}\text { Operative time, mean } \pm \text { SD } \\
\text { (range) }[\mathrm{min}]\end{array}$ & $126.9 \pm 33.5(70-200)$ \\
\hline $\begin{array}{l}\text { Stent insertion time, mean } \pm \text { SD } \\
\text { (range) [min] }\end{array}$ & $2.61 \pm 0.8(1.5-5)$ \\
\hline Conversion to open & None \\
\hline $\begin{array}{l}\text { Crossing vessels in pyeloplasty } \\
\text { group, } n(\%)\end{array}$ & $9 / 32(28.1)$ \\
\hline Upper/mid ureteral stone & $6 / 4$ \\
\hline $\begin{array}{l}\text { Stone diameter, mean } \pm \text { SD } \\
\text { (range) }[\mathrm{mm}]\end{array}$ & $28.2 \pm 14.7(18-44)$ \\
\hline Solitary kidney, n (\%) & $1(2.3)$ \\
\hline $\begin{array}{l}\text { Hospital stay, mean } \pm \text { SD (range) } \\
\text { [days] }\end{array}$ & $2.8 \pm 0.9(2-5)$ \\
\hline
\end{tabular}


paediatric cases and in all LUUT procedures in our study.

The transperitoneal approach was preferred in all cases except two. This decision was based on our clinical experience and provided convenience in the antegrade placement of stents by offering a large area. Approaches such as infusing the bladder with methylene blue or similar substances, or checking with ultrasonography to confirm the placement of the distal tip of the stent, were not deemed necessary. In case of difficulties in advancing the closed distal tip of the stent or if it appeared to be stuck, advancing into the distal tip was continued by lightly pulling the guide back within the stent and softening its tip. It was determined in only 1 case that the stent had not entered the bladder and had been dislocated. Gas leakage was minimized by using a $14 \mathrm{Fr}$ for the $4.8 \mathrm{Fr} \mathrm{D} / \mathrm{J}$ and a $10 \mathrm{Fr}$ for the $4 \mathrm{Fr} \mathrm{D} / \mathrm{J}$.

\section{Conclusions}

Amplatz dilators, which can be found in almost all clinics offering endourological procedures, provide convenience and eliminate the difficulties encountered during the antegrade utilization of the $\mathrm{D} / \mathrm{J}$ stents used in LUUT procedures to increase the durability of the anastomosis and prevent extravasation. The limitations of our study can be summarized as the absence of randomization with a control group and other techniques, and our short follow-up time. Future studies carried out with a greater number of cases and a control group will be valuable for revealing the success and reliability of this technique.

\section{Conflict of interest}

The authors declare no conflict of interest.

\section{References}

1. Kwon YU, Lee SI, Jeong TY. Treatment of upper and mid ureter stones: comparison of semirigid ureteroscopic lithotripsy with holmium: YAG laser and shock wave lithotripsy. Korean J Urol 2007; 48: 171-5.

2. Kijvikai K, Patcharatrakul S. Laparoscopic ureterolithotomy: Its role and some controversial technical considerations. Int J Urol 2006; 13: 206-10

3. Lee YS, Lee DH, Han WK, et al. Laparoscopic ureterolithotomy has a role for treating ureteral stones. Korean J Urol 2006; 47: 498-501.

4. Türk C, Petřík A, Sarica K, et al. EAU guidelines on interventional treatment for urolithiasis. Eur Urol 2016; 69: 475-82.
5. Piaggio LA, Franc-Guimond J, Noh PH, et al. Transperitoneal laparoscopic pyeloplasty for primary repair of ureteropelvic junction obstruction in infants and children: comparison with open surgery. J Urol 2007; 178: 1579-83.

6. Tasian GE, Casale P. The robotic-assisted laparoscopic pyeloplasty: gateway to advanced reconstruction. Urol Clin North Am 2015; 42: 89-97.

7. Huang $\mathrm{Y}, \mathrm{Wu} \mathrm{Y}$, Shan $\mathrm{W}$, et al. An updated meta-analysis of laparoscopic versus open pyeloplasty for ureteropelvic junction obstruction in children. Int J Clin Exp Med 2015; 8: 4922-31.

8. Shkodkin SV, Kogan MI, Lyubushkin AV, et al. Complications of stenting of upper urinary tract. Urologiia 2015; 1: 94-8.

9. Ko YH, Kang SG, Park JY, et al. Laparoscopic ureterolithotomy as a primary modality for large proximal ureteral calculi: comparison to rigid ureteroscopic pneumatic lithotripsy. J Laparoendosc Adv Surg Tech A 2011; 21: 7-13.

10. Şahin S, Aras B, Ekşi M, et al. Laparoscopic ureterolithotomy. JSLS 2016; 20: 1-7.

11. Arumainayagam N, Minervini A, Davenport K, et al. Antegrade versus retrograde stenting in laparoscopic pyeloplasty. J Endourol 2008; 22: 671-4.

12. Chandrasekharam VV. Is retrograde stenting more reliable than antegrade stenting for pyeloplasty in infants and children? Urology 2005; 66: 1301-4.

13. Mandhani A, Goel S, Bhandari M. Is antegrade stenting superior to retrograde stenting in laparoscopic pyeloplasty? J Urol 2004; 171: 1440-2.

14. Eassa W, Al Zahrani A, Jednak R, et al. A novel technique of stenting for laparoscopic pyeloplasty in children. J Pediatr Urol 2012; 8: 77-82.

15. Kim HS, Lee BK, Jung JW, et al. J-tube technique for double-j stent insertion during laparoscopic upper urinary tract surgical procedures J Endourol 2014; 28: 1278-81.

16. Yu J, Wu Z, Xu Y, et al. Retroperitoneal laparoscopic dismembered pyeloplasty with a novel technique of JJ stenting in children. BJU Int 2011; 108: 756-9.

17. Derouiche A, El Atat R, Ben Slama MR, Chebil M. Endoscopic bridge operating-guide device applied for intracorporeal antegrade ureteric stenting during laparoscopic pyeloplasty. J Endourol 2009; 23: 1871-4.

18. Noh PH, Defoor WR, Reddy PP. Percutaneous antegrade ureteral stent placement during pediatric robot-assisted laparoscopic pyeloplasty. J Endourol 2011; 25: 1847-51.

19. Minervini A, Siena G, Masieri L, et al. Antegrade stenting in laparoscopic pyeloplasty: feasibility of the technique and time required for stent insertion. Surg Endosc 2009; 23: 1831-4.

20. Kalkan S, Ersöz C, Armagan A, et al. Modified antegrade stenting technique for laparoscopic pyeloplasty in infants and children. Urol Int 2016; 96: 183-7.

Received: 3.04 .2018 , accepted: 25.06 .2018 